\title{
PENGARUH PEMINDAHAN PERPUSTAKAAN UMUM KABUPATEN REMBANG KE LOKASI PARIWISATA PANTAI KARTINI TERHADAP MINAT KUNJUNG PEMUSTAKA
}

\author{
Athiyah Kamaliyah*
}

\begin{abstract}
The aim of this research are (1) to know the influence of Rembang Public Library transfer to Kartini Beach tourism area toward animo of visits to the libraryt (2) to know user perception about Rembang Public Library transfer to Kartini Beach tourism area (3) to know animo of visits to Rembang Public Library. This was a quantitative research that used correlation method between location (independent variable) and animo of visits (dependent variable). Data were collected through questionnaire, interview and documentation. Data analysis used product moment correlation and processed using SPSS version 17 for Windows. The result of the study showed there was significant correlation between location and animo of visits. Score of correlation was 0.632 at significance level $5 \%$ r table is 0.202 . The Rembang public library transfer to Kartini Beach tourism area belonged to good category whereby grand mean of location variable was 2.86. Animo of visits also belonged to high category whereby grandmean was 3.01 .
\end{abstract}

Key word: location, animo of visit, public library

* Alumni Universitas Islam Negeri Sunan Kalijaga

\section{PENDAHULUAN}

Menurut Undang-Undang Republik Indonesia Nomor 43 Tahun 2007 pasal 1 ayat 6, perpustakaan umum adalah perpustakaan yang diperuntukkan bagi masyarakat luas sebagai sarana pembelajaran sepanjang hayat tanpa membedakan umur, jenis kelamin, suku, ras, agama, dan status sosial ekonomi. Daryono (2009) menyebutkan bahwa perpustakaan umum mempunyai peran strategis dalam meningkatkan taraf hidup masyarakat, sebagai sarana belajar seumur hidup guna mengembangkan potensi masyarakat agar menjadi manusia yang berilmu sehingga dapat mendukung penyelenggaraan pendidikan guna mencerdaskan bangsa. Melalui perpustakaan juga, warga masyarakat dapat memberdayakan diri dengan mendapatkan berbagai informasi yang sesuai dengan kebutuhan profesi dan bidang tugas masing-masing. Pada akhirnya bermuara pada tumbuhnya warga masyarakat yang well-informed, berkualitas dan demokratis (Siregar, 2004:75).

Keberadaan perpustakaan umum di berbagai kota atau kabupaten di Indonesia belum berkembang dengan memuaskan. Hal ini diidentifikasi dari banyak warga masyarakat yang tidak pernah berkunjung ke perpustakaan. Parahnya, di antara warga masyarakat tersebut tidak mengetahui lokasi perpustakaan di kota mereka (Siregar, 2004:75). Hal ini sangat memperihatinkan, mengingat peran perpustakaan umum dalam masyarakat sangat penting. Oleh sebab itu, perpustakaan umum berusaha memasyarakatkan fungsi dan kegunaan perpustakaan dengan cara mendekatkan diri kepada masyarakat. Salah satu caranya yaitu dengan menempatkan perpustakaan pada lokasi yang strategis sehingga mudah diakses masyarakat.

Menurut Sutarno (2006:42) lokasi menjadi aspek utama yang harus diperhatikan pada pembangunan perpustakaan. Dilihat dari segi lokasi, pengguna akan melihat jauh dekatnya perpustakaan, tidak membutuhkan banyak waktu, tenaga dan biaya. Pemilihan lokasi menurut Sulistyo-Basuki (1993:307) hendaknya memperhitungkan kenyamanan, perluasan masa mendatang, ketersediaan tanah, dan dana. Lokasi perpustakaan berpengaruh besar terhadap pemakai, misalnya perpustakaan umum yang jauh dari fasilitas angkutan umum pasti akan berkurang pengunjungnya. Oleh karena itu, hendaknya perpustakaan umum ditempatkan pada lokasi yang sering dan mudah dikunjungi 
oleh umum bahkan kalau mungkin di pusat kegiatan masyarakat seperti pertokoan atau dekat fasilitas umum.

Arsip Perpustakaan Umum Kabupaten Rembang, Perpustakaan Urnum Kabupaten Rembang beberapa kali mengalami pemindahan lokasi. Terakhir sebelum tahun 2009, Perpustakaan Umum Kabupaten Rembang berada di komplek rumah dinas bupati Rembang yaitu jalan Gatot Soebroto nomor 8 Rembang. Letaknya yang tidak strategis membuat perpustakaan ini sepi dari pengunjung. Artikel yang dimuat oleh situs bernama Pantura Pos pada tanggal 8 Juli 2009, menyebutkan jumlah pengunjung per hari paling banyak 30 orang. Kemudian berdasarkan Peraturan Daerah Kabupaten Rembang Nomor 12 Tahun 2008, Perpustakaan Umum Kabupaten Rembang menempati bangunan yang lebih representatif di komplek Taman Rekreasi Pantai Kartini Jalan Diponegoro No. 25 Rembang. Pemindahan lokasi gedung ini diharapkan bisa menjadi salah satu faktor untuk meningkatkan tingkat kunjungan pemustaka.
Keberadaan Perpustakaan Umum Kabupaten Rembang diharapkan menjadi pusat pendidikan non formal bagi masyarakat Rembang, terutama mereka yang tinggal di wilayah Tasik Agung (desa tempat perpustakaan berada). Perpustakaan tersebut terus menjalankan perannya dalam usaha peningkatan kebudayaan dan perkembangan kemajuan masyarakat setempat. Surat kabar Jateng Pos Online 14 Maret 2015, perpustakaan selalu melakukan berbagai upaya untuk menarik minat kunjung, diantaranya mengadakan pameran buku murah, penambahan koleksi, dan menyediakan fasilitas wifi. Tidak hanya itu, perpustakaan juga menyediakan fasilitas mobil untuk pelayanan peminjaman buku. Sayangnya, hal ini belum mampu meningkatkan kunjungan pemustaka ke perpustakaan. Bahkan jumlah kunjungan dalam kurun waktu terakhir yaitu tahun 2013 dan 2014 menurun.

Tabel 1

Rekapitulasi Pengunjung Perpustakaan Umum Kabupaten Rembang Tahun 2013 dan 2014

\begin{tabular}{lcc}
\hline \multirow{2}{*}{ BULAN } & \multicolumn{2}{c}{ TAHUN } \\
\cline { 2 - 3 } & $\mathbf{2 0 1 3}$ & $\mathbf{2 0 1 4}$ \\
\hline Januari & 1366 & 1342 \\
\hline Februari & 1298 & 1251 \\
\hline Maret & 1271 & 1260 \\
\hline April & 1241 & 1192 \\
\hline Mei & 1257 & 1289 \\
\hline Juni & 1182 & 1145 \\
\hline Juli & 970 & 1157 \\
\hline Agustus & 938 & 808 \\
\hline September & 1087 & 982 \\
\hline Oktober & 1175 & 1087 \\
\hline Nopember & 1335 & 1250 \\
\hline Desember & 1443 & 1509 \\
\hline JUMLAH & $\mathbf{1 4 5 6 3}$ & $\mathbf{1 4 2 7 2}$ \\
\hline Sumber: Perpustakaan Umum Kabupaten Rembang
\end{tabular}

Tabel di atas menunjukkan ada penurunan dan kenaikan jumlah pengunjung perpustakaan. Penurunan terjadi pada bulan Januari, Februari, Maret, April, Juni, Agustus, September, Oktober, dan Nopember. Sedangkan kenaikan jumlah pengunjung perpustakaan terjadi pada bulan Mei, Juli dan Desember. Jika dibuat perbandingan antara penurunan dan kenaikan jumlah pengunjung perpustakaan maka angka yang mewakili yaitu $3: 1$.
Survei awal yang dilakukan oleh peneliti tanggal 17 Februari 2015 dan wawancara secara langsung dengan Bapak Yazid Aris Khoiron, ST. selaku Kepala Seksi Perpustakaan Umum Kabupaten Rembang, didapatkan sejumlah informasi penting berkaitan dengan pemindahan lokasi perpustakaan. Perpustakaan umum kabupaten Rembang resmi di pindahkan ke komplek wisata pantai Kartini pada tahun 2008. 
Pemindahan lokasi ini dilandasi oleh beberapa alasan yaitu (1) Gedung perpustakaan berada satu atap dengan Museum Kartini (2) Ruangan yang digunakan untuk koleksi perpustakaan terlalu sempit (3) Lokasi perpustakaan jauh dari jalan raya sehingga susah diakses dengan kendaraan umum (4) Banyak masyarakat yang malu datang ke perpustakaan karena harus melewati pintu gerbang kabupaten (5) Gedung gereja yang berada di komplek wisata pantai Kartini tidak digunakan lagi sejak tahun 2003.

Berdasarkan dari uraian latar belakang di atas, penelitian dengan judul "Pengaruh Pemindahan Perpustakaan Umum Kabupaten Rembang ke Lokasi Pariwisata Pantai Kartini Terhadap Minat Kunjung Pemustaka".

\section{Rumusan Masalah}

Berdasarkan latar belakang, peneliti merumuskan masalah sebagai berikut.

1. Adakah pengaruh antara pemindahan perpustakaan umum kabupaten Rembang ke lokasi pariwisata pantai kartini dan minat kunjung pemustaka?

2. Bagaimana persepsi pemustaka tentang pemindahan lokasi Perpustakaan Umum Kabupaten Rembang ke lokasi pariwisata Pantai kartini?

3. Bagaimana minat kunjung pemustaka di Perpustakaan Umum Kabupaten Rembang?

\section{LANDASAN TEORI}

\section{Lokasi Perpustakaan}

Menurut Kamus Besar Bahasa Indonesia (1990:530) lokasi memiliki arti (1) letak (2) tempat: lokasi merupakan tempat dimana suatu bangunan itu berada. Bagi perpustakaan, lokasi menjadi tempat berlangsungnya kegiatan perpustakaan dalam melayani pemustaka dengan menyediakan berbagai sumber informasi. Penentuan lokasi yang tepat sangat penting bagi kelangsungan sebuah perpustakaan. Koontz dalam Siregar (2011:12) mengemukakan bahwa keberhasilan penyelenggaraan perpustakaan umum tergantung pada berbagai faktor diantaranya pemilihan lokasi. Selanjutnya disebutkan bahwa pemilihan lokasi perpustakaan umum merupakan suatu keputusan penting yang dibuat oleh perencana kota.

Perpustakaan umum dapat berperan lebih besar untuk mendukung peningkatan kualitas sumber daya manusia apabila fasilitas ini mudah dijangkau, memiliki daya tarik, dan menyediakan pelayanan yang sesuai dengan kebutuhan masyarakat. Dengan kata lain peran yang optimal dapat dicapai apabila memiliki aksesibilitas yang tinggi dari suatu masyarakat penggunanya. Menurut Siregar (2011:85) aksesibilitas tinggi pada suatu perpustakaan tergantung pada bebcrapa faktor, yaitu: faktor lokasi, prasarana pendukung lokasi, karakteristik demografi, motivasi pengguna, spesifikasi fisik fasilitas, dan operasional perpustakaan.

Dua dari enam faktor tersebut di atas berkaitan dengan topik penelitian ini, yaitu:

1. Lokasi adalah letak perpustakaan yang berkaitan dengan jarak tempat tinggal, tempat bekerja/sekolah/kampus pengguna dan waktu tempuh yang dibutuhkan untuk mencapai lokasi.

2. Prasarana pendukung lokasi adalah seluruh prasarana yang mendukung pencapaian lokasi perpustakaan dalam rangka penggunaan perpustakaan.

a. Peta lokasi adalah petunjuk yang dapat memudahkan pengguna untuk mengetahui lokasi perpustakaan.

b. Trayek angkutan umum adalah moda transportasi yang tersedia dari tempat tinggal/ bekerja/ sekolah/ kampus pengguna untuk menjangkau lokasi perpustakaan.

c. Fasilitas jalan utama adalah jalan yang langsung menuju lokasi dari tempat tinggal/ bekerja/ sekolah/ kampus pengguna.

d. Trotoar adalah fasilitas bagi pengguna yang berjalan kaki untuk menjangkau lokasi perpustakaan.

e. Koridor adalah bangunan penghubung dari tempat pemberhentian kendaraan umum dan pribadi menuju lokasi perpustakaan.

f. Kondisi prasarana jalan adalah kualitas prasarana jalan untuk menjangkau lokasi perpustakaan.

g. Petunjuk jalan adalah sistem petunjuk yang dapat digunakan untuk memandu pengguna menuju lokasi perpustakaan.

Pendapat lain dikemukakan oleh Tjjptono (2009:92) mengenai pertimbangan-pertimbangan dalam menentukan lokasi, yaitu:

1. Akses, misalnya lokasi yang dilalui atau mudah 
dijangkau dengan sarana transportasi umum.

2. Visibilitas yaitu keberadaan lokasi yang dapat dilihat dengan jelas dari tepi jalan.

3. Lalu lintas (traffic), menyangkut dua pertimbangan utama, yaitu:

a) Banyaknya orang lalu lalang bisa memberikan peluang terjadinya hasrat atau dorongan membeli.

b) Kepadatan dan kemacetan lalu lintas bisa pula inenjadi hambatan, misalnya ambulans.

4. Tempat parkir yang luas, nyaman dan aman, baik untuk kendaraan roda dua maupun roda empat.

5. Ekspansi, tersedia tempat yang cukup luas untuk perluasan usaha di kemudian hari.

6. Lingkungan, yaitu daerah sekitar yang mendukung barang dan jasa yang ditawarkan.

7. Kompetisi, yaitu lokasi pesaing.

8. Peraturan pemerintah, misalnya ketentuan yang melarang sebuah bangunan berdiri di atas tanah tertentu.

Padilla (2002:3-17) dalam karyanya yang berjudul Site Selection for Libraries mengatakan ada beberapa faktor yang harus dipertimbangkan saat pemilihan lokasi perpustakaan.

\section{Keadaan Lokasi (Site Context)}

Keadaan lokasi perpustakaan harus benar-benar benar diperhatikan baik secara geografi, kebebasan tanah, infrastuktur tanah, topografi dan perizinan. Secara geografi lokasi harus berada di pusat kegiatan masyarakat ditentukan jarak, akses, penyebaran populasi dan sekolah. Lokasi yang digunakan sebagai perpustakaan haruslah jelas status tanahnya, milik perpustakaan. Infrastruktur tanah menentukan bentuk bangunan dan kebutuhan dari perpustakaan itu sendiri. Misalnya perpustakaan berada di wilayah dataran tinggi, maka bangunan yang dibuat akan berbeda dengan yang ada di dataran rendah. Maksud dari topografi disini adalah kemiringan suatu tanah yang berpengaruh pada curah hujan suatu daerah dan suhu udara. Masalah perizinan ini tergantung dari persetujuan pemerintah daerah yang akan dibangun perpustakaan.

\section{Kesesuaian Lokasi (Site Fit)}

Lokasi yang akan dijadikan perpustakaan harus dievaluasi apakah sesuai dengan proyek yang akan dibuat atau tidak. Misalkan, harus ada tempat parkir yang memadai, taman hijau, parkir bawah tanah harus diukur dengan luas tanah yang ada. Setelah sesuai, perlu juga dipikirkan perkembangan masa depan bangunan perpustakaan. Agar saat dilakukan perluasan bangunan baik ke atas atau ke samping masih ada lahan yang dapat digunakan.

\section{Aksesibilitas (Accessibility)}

Sebuah perpustakaan umum hendaknya mudah dijangkau masyarakat baik dengan jalan kaki maupun dengan kendaraan. Berikut akses yang harus disediakan oleh sebuah perpustakaan:
a. Akses Kendaraan
b. Transportasi Massa
c. Pejalan kaki dan Sepeda
d. Akses umum
e. Layanan akses

\section{Orientasi Lokasi (Site Orientation)}

Orientasi lokasi akan berpengaruh pada detail dari konstruksi bangunan. Pengetahuan tentang sinar matahari dan tiupan angin di wilayah tersebut sangat penting untuk bangunan. Pengetahuan ini akan mempermudah dalam mengevaluasi penempatan yang sesuai untuk sebuah perpustakaan pada lokasi tertentu. Cahaya matahari yang cukup dapat digunakan untuk penerangan dan angin yang ada dapat digunakan sebagai sirkulasi udara. Hal ini akan menghemat biaya penggunaan lampu dan pendingin ruangan.

Berdasarkan uraian tersebut di atas, pada penelitian ini menggunakan teori yang dikemukakan oleh Tjiptono (2009:92) dalam menentukan lokasi perpustakaan. Alasan penggunaan teori ini didasarkan pada 5 teori yang dimiliki Tjiptono sudah mampu mewakili apa yang terdapat pada teori milik Padilla dan Siregar. Misalnya visibilitas, pada teori Siregar dan Padilla tidak ada penjelasan mengenai hal tersebut. Agar lebih jelas bisa dilihat pada tabel perbandingan berikut.

Tabel 2

Perbandingan Teori

\begin{tabular}{lll}
\hline \multicolumn{1}{c}{ Siregar } & \multicolumn{1}{c}{ Padilla } & \multicolumn{1}{c}{ Tjiptono } \\
\hline 1. Lokasi & 1. Keadaan lokasi & 1. Akses \\
2. Prasarana & 2. Kesesuain lokasi & 2. Visibilitas \\
pendukung & 3. Akscsibilitas & 3. Lalu lintas \\
lokasi & 4. Orientasi lokasi & 4. Tempat parkir \\
& & 5. Lingkungan \\
\hline
\end{tabular}

Sumber: Siregar(2011:110), Padilla (2002:3-17)

dan Tjiptono (2009:92) 
Terdapat 8 indikator dalam teori tersebut namun, peneliti hanya menggunakan 5 indikator. Tiga indikator yang tidak digunakan yaitu ekspansi, kompetisi, dan peraturan pemerintah. Alasan peneliti tidak mengambil ketiga indikator tersebut karena (1) ckspansi berkaitan dengan ketcrsediaan lahan yang cukup luas untuk perluasan bangunan di kemudian hari (2) Kompetisi berkaitan dengan lokasi pesaing, misalnya dalam menentukan lokasi wartel (warung telekomunikasi) perlu dipertimbangkan jumlah wartel yang ada di daerah yang sama (3) Peraturan pemerintah berkaitan dengan izin mendirikan bangunan, ketinggian maksimal bangunan, larangan membangun di wilayah tertentu dan peraturan lainnya. Indikator tersebut hanya diketabui oleh instansi terkait dalam hal ini perpustakaan. Pemustaka tidak mengetahui bagaimana ekspansi, kompetisi dan peraturan pemerintah yang mengatur suatu lokasi suatu perpustakaan serta sesuai dengan kondisi Perpustakaan Umum Kabupaten Rembang.

\section{Minat Kunjung}

Minat seseorang terhadap sesuatu adalah kecenderungan hati yang tinggi, gairah atau keinginan seseorang tersebut terhadap sesuatu (Sutarno, 2006:26). Kunjungan sendiri berasal dari kata kunjung yang mendapat akhiran -an memiliki makna hal perbuatan mengunjungi atau berkunjung (Poerwadarminta, 2011:635). Lasa (2009:183) dalam "Kamus Kepustakawanan Indonesia" mendefinisikan kunjungan ke perpustakaan adalah kegiatan memasuki perpustakaan untuk melakukan akses informasi dan kegiatan lain di perpustakaan yang tercatat secara manual maupun elektronik. Definisi minat kunjung perpustakaan adalah keinginan seseorang mengunjungi perpustakaan untuk memanfaatkan fasilitas perpustakaan dalam waktu tertentu.

Sutarno (2006:29) menjelaskan faktor yang mendorong bangkitnya minat antara lain:

1. Rasa ingin tahu yang tinggi

Rasa ingin tahu menjadi bukti bahwa dalam diri seseorang terdapat minat yang dapat dikembangkan, namun perlu adanya dukungan fisik dan lingkungan sosial.

2. Keadaan lingkungan yang memadai

Keadaan lingkungan yang memadai berpengaruh positif terhadap minat kunjung pemustaka, sehingga pustakawan perlu menimbang faktor lingkungan. Faktor yang perlu dipertimbangkan misalnya tata letak kursi, pencahayaan yang bagus, ruangan bersih ditambah pustakawan melayani dengan ramah.

3. Berprinsip hidup bahwa kunjungan ke perpustakaan adalah kebutuhan: kebutuhan terbadap suatu informasi, kebutuhan untuk mendapatkan buku-buku atau bahan bahan pustaka lain, kebutuhan akan fasilitas perpustakaan yang menunjang kegiatan belajar, dan kebutuhan untuk mendapatkan bimbingan dari pustakawan untuk mendapatkan apa yang diinginkan.

\section{METODE PENELITIAN}

Ditinjau dari pendekatan analisisnya, penelitian ini termasuk penelitian kuantitatif. Penelitian kuantitatif adalah suatu proses menemukan pengetahuan yang menggunakan data berupa angka sebagai alat menganalisis keterangan mengenai apa yang ingin kita ketahui (Kasiram, 2010:172).

Populasi yang digunakan dalam penelitian ini yaitu anggota Perpustakaan Umum Kabupaten Rembang yang tercatat pada sistem informasi perpustakaan tahun 2014 yang berjumlah 3.272 orang. Anggota tersebut terdiri dari SD, SMP, SMA, mahasiswa, karyawan dan umum. Pengklasifikasian anggota perpustakaan didasarkan pada status pendidikan dan pekerjaannya. Dalam penelitian ini, perbedaan status tersebut tidak digunakan sebagai pembeda karena didasarkan pada asumsi bahwa mereka memiliki kepentingan yang sama terhadap pelayanan perpustakaan. Begitu juga dengan pihak perpustakaan yang tidak membedakan layanan berdasarkan pendidikan dan pekerjaan.

Dalam menentukan sampel, peneliti menggunakan rumus Slovin dalam Sudjarwo dan Basrowi (2009:269) dengan memasukkan angka populasi sebanyak 3.272 orang anggota perpustakaan, berikut ini perhitungannya.

$$
\begin{aligned}
& n=\frac{N}{1+N e^{2}} \\
& n=\frac{3272}{1+3272(0.1)^{2}} \\
& n=\frac{3272}{1+32,72} \\
& n=97,03 \text { dibulatkan menjadi } 97 \text { orang }
\end{aligned}
$$

Keterangan: $\mathrm{n}=$ jumlah sampel; $\mathrm{N}=$ populasi; $\mathrm{e}=$ kesalahan yang masih dapat ditolerir. 
Teknik pengambilan sampel untuk penelitian ini menggunakan insidental sampling. Sampling Insidental adalah teknik penentuan sampel berdasarkan kebetulan, yaitu siapa saja yang secara kebetulan bertemu dengan peneliti dapat digunakan sebagai sampel, bila dipandang orang yang ditemui cocok sebagai sumber data (Sugiyono, 2013:85). Alasan peneliti menggunakan sampling insidental karena jumlah populasi cukup besar, peneliti tidak mendapatkan data-data yang lengkap mengenai anggota perpustakaan, biaya dan waktu yang tersedia untuk melakukan penelitian terbatas.

Peneliti menggunakan 3 metode pengambilan data yaitu kuesioner, wawancara dan dokumentasi. Data tersebut kemudian dianalisis dengan menggunakan rumus sebagai berikut

$$
X=\frac{\sum x}{N}
$$

Keterangan:

$X \quad$ rata-rata hitung;

$\sum X=$ jumlah semua nilai kuesioner;

$N \quad=$ jurnlah responden

2. Grand Mean $(x)=\frac{\text { iotal rata-ratehitumg }}{\text { iumat rosponden }}$

\section{Product Moment}

Peneliti menggunakan rumus korelasi Product Moment untuk mengetahui adakah pengaruh pemindahan lokasi Perpustakaan Umum Kabupaten Rembang ke lokasi pariwisata Pantai Kartini terhadap minat kunjung pemustaka. Dalam hal ini digunakan ketentuan apabila $\mathbf{r}$ hitung $\geq$ nilai $r$ tabel maka korelasinya signifikan dan sebaliknya apabila $r$ hitung $\leq \mathrm{r}$ tabel maka korelasinya tidak signifikan.

$$
r_{x y y}=\frac{N \sum x y-\left(\sum x\right)\left(\sum y\right)}{\sqrt{\left(N \sum x^{2}-\left(\sum x\right)^{2}\right)\left(N \sum y^{2}-\left(\sum y\right)\right)}}
$$

Ketcrangan:

$r_{* y}$ - Koefisien kurelasi antara skor butir dengan skor total

$N=$ Juntala subjek uji cola

$\Sigma x=$ Jumlah skor butir $(\mathrm{x})$

$\sum x^{2}=$ Jumlah skor butir knadrat (x)

$\sum y=$ Jumlin skor total (y)

$\sum y^{2}-$ Jumblah stior total kuadrat (Y)

$\sum x y=$ Junlah per kalian skor total butir dengan skor total

\section{HASIL DAN PEMBAHASAN}

Peneliti menyebarkan kuesioner kepada 97 responden dengan jumlah pernyataan 19 butir. Adapaun pernyataan tersebut terdiri dari variabel lokasi sebanyak 13 butir dan variabel minat kunjung sebanyak 6 butir. Berikut ini hasil akhir dari perhitungan variabel lokasi dan minat kunjung setelah dilakukan perhitungan menggunakan rumus mean dan grand mean.

Tabel 3

\begin{tabular}{|c|c|c|c|c|}
\hline No. & Indikator Lokasi & $\begin{array}{c}\text { Nilai } \\
\text { Rata-rata }\end{array}$ & Kategori & $\begin{array}{c}\text { Total } \\
\text { Nilai } \\
\text { rata-rata }\end{array}$ \\
\hline & Akses & 2,89 & Baik & \multirow{6}{*}{2,86} \\
\hline 2. & Visibilitas & 2,78 & Baik & \\
\hline & Lalu lintas (Traffic) & 2,66 & Baik & \\
\hline & Tempat parkir & 2,71 & Baik & \\
\hline & Lingkungan & 3,25 & Baik & \\
\hline \multicolumn{2}{|c|}{ Jumlah } & 14,29 & & \\
\hline
\end{tabular}

Jawaban responden tentang variabel lokasi

Sumber: Data Primer Diolah Bulan Mei 2015

Tabel 2 di atas menunjukkan bahwa secara keseluruhan lokasi Perpustakaan Umum Kabupaten Rembang baik dengan nilai rata-rata 2,86 . 
Tabel 4

Jawaban responden tentang minat kunjung

\begin{tabular}{llccc}
\hline No. $\quad$ Indikator Lokasi & $\begin{array}{c}\text { Nilai } \\
\text { Rata-rata }\end{array}$ & Kategori & $\begin{array}{c}\text { Total } \\
\text { Nilai } \\
\text { rata-rata }\end{array}$ \\
\cline { 1 - 2 } 1. & Rasa ingin tahu & 3,14 & Tinggi & \multirow{2}{*}{3,01} \\
\cline { 1 - 2 } 2. & Keadaan lingkungan & 2,82 & Tinggi & \\
\cline { 1 - 2 } 3. & Kebutuhan informasi & 3,07 & Tinggi & \\
\hline Jumlah & 9,03 & \\
\hline
\end{tabular}

Sumber: Data Primer Diolah Pada Bulan Mei 2015

Tabel 3 di atas menunjukkan bahwa secara keseluruhan minat kunjung pemustaka di Perpustakaan Umum Kabupaten Rembang tinggi dengan nilai rata-rata 3,01.

Model analisis korelasi product moment ini digunakan untuk mengetahui pengaruh pemindahan Perpustakaan Umum Kabupaten Rembang ke lokasi Pariwisata Pantai Kartini terhadap minat kunjung pemustaka. Perhitungan korelasi product moment ini dihitung menggunakan alat bantu berupa software aplikasi SPSS version 17 for windows.

Tabel 5

Hasil Korelasi Product Moment

Correlations

\begin{tabular}{llrr}
\multicolumn{3}{c}{ Correlations } & \\
\hline Lokasi & & Lokasi & Minat Kunjung \\
& Pearson Correlation & 1 & $.632^{* *}$ \\
& Sig. (2-tailed) & & .000 \\
& $\mathrm{~N}$ & 97 & 97 \\
\hline Minat Kunjung & Pearson Correlation & $.632^{* *}$ & 1 \\
& Sig. (2-tailed) & .000 & \\
& $\mathrm{~N}$ & 97 & 97 \\
\hline
\end{tabular}

**. Correlation is significant at the 0.01 level (2tailed).

Sumber: Data primer yang diolah bulan Mei 2015

Hasil korelasi product moment pada tabel $4 \mathrm{di}$ atas dapat diketahui bahwa nilai koefisien korelasi antara lokasi dan minat kunjung adalah sebesar 0,632 . Sementara nilai $r$ tabel dengan $N=97$,jika dibitung $\mathrm{df}=\mathrm{N}-2$, jadi $\mathrm{df}=97-2=95$ dan didapat $\mathbf{r}$ tabel pada taraf signifikasi $5 \%$ adalah 0,202 (Sugiyono, 2013: 184). Jadi, nilai $r$ hitung $=0,632>$ r tabel $=0,202(\alpha=5 \%)$.
Menurut Sugiyono (2013:184) nilai koefisien korelasi $0,60-0,799$ dikategorikan kuat. Koefisien korelasi dari tabel diatas menunjukkan angka 0,632 maka intepretasi pengaruh pemindahan lokasi Perpustakaan Umum Kabupaten Rembang ke lokasi Pariwisata Pantai Kartini terhadap minat kunjung pemustaka adalah kuat. Berdasarkan hasil analisis tersebut, dapat ditarik simpulan bahwa hipotesis kerja (Ha) diterima. Dalam hal ini berarti ada pengaruh antara pemindahan Perpustakaan Umum Kabupaten Rembang ke lokasi Pariwisata Pantai Kartini terhadap minat kunjung pemustaka.

\section{KESIMPULAN}

Berdasarkan analisis hasil penelitian di atas, maka dapat disimpulkan sebagai berikut:

1. Pemindahan Perpustakaan Umum kabupaten Rembang ke lokasi pariwisata Pantai Kartini dikategorikan baik dengan skor rata-rata 2,86 didapatkan dari hasil penelitian dengan indikator akses, visiblitas, lalu lintas (traffic), tempat parkir dan lingkungan.

2. Minat kunjung pemustaka di Perpustakaan Umum Kabupaten Rembang dikategortkan tinggi dengan skor rata-rata 3,01 didapatkan dari hasil penelitian dengan indikator rasa ingin tahu, keadaan lingkungan dan kebutuhan informasi.

3. Ada pengaruh antara pemindahan Perputstakaan Umum Kabupaten Rembang ke lokasi pariwisata Pantai Kartini dan minat kunjung pemustaka. Hal itu bisa dilihat dari uji hipotesis dengan menggunakan analisis korelasi product moment didapatkan hasil 0,632 . Pada taraf $5 \%$ dengan nilai $\mathrm{r}$ tabel 
sebesar 0,202 artinya nilai koefisien korelasi lebih besar dibandingkan nilai $r$ tabel. Hasil uji hipotesis tersebut sekaligus menjawab bahwa hipotesis kerja diterima.

\section{DAFTAR PUSTAKA}

Daryono.2009.'Pengembangan Perpustakaan Umum Daerah dan Perpustakaan Sekolah Kota Solo". Diakses dari $\mathrm{h}$ ttp://daryono.staff. uns.ac.id/2009/02/12/pengembanganperpustakaan-umum-daerah-danperpustakaan-sekolah-kota-surakartal, pada tanggal 23 April 2014 pukul 10.35 WIB.

Indonesia, Departemen Pendidikan dan Kebudayaan. 1990. Kamus Besar Bahasa Indonesia. Jakarta: Balai Pustaka.

Jateng Pos. 2015. "Pengunjung Perpusda Terus M e n r u n". Diakses d a $\mathrm{i}$ ht tp: //jateng pos.co/pat $i$ pos/view/2015/03/14/pengunjung-perpusdaterus-menurun, pada tanggal 17 Maret 2015 pukul 19.30 WIB.

Kasiram, H. Moh. 2010. Metodologi Penelitian Kuantitatif-Kualitatif. Malang: UIN Malang Press.

Lasa HS. 2009. Kamus Kepustakawanan. Yogyakarta: Pustaka Book Publisher.
Padilla, Lisa. 2002. "Site Selection for Libraries". Diakses dan diunduh dari http://www.librisdesign.org/docs/siteselectio nlibraries.pdf, pada tanggal 22 April 2014 pukul21.30 WIB.

Pemerintah Republik Indonesia. 2007. Undangundang Republik Indonesia No. 43 Tahun 2007 Tentang Perpustakaan. Jakarta.

Poerwadarminta, W.J.S.2011.Kamus Umum Bahasa Indonesia Edisi III. Jakarta: Balai Pustaka.

Siregar, A. Ridwan. 2004. Perpustakaan: Energi Pembangunan Bangsa. Medan: USU Press. 2011. Perencanaan Lokasi Perpustakaan Umum Spasial di Wilayah Perkotaan. Medan: USU Press.

Sudjarwo dan Basrowi.2009. Manajemen Penelitian Sosial. Bandung: Mandar Maju.

Sugiyono. 2013. Metode Penelitian Kuantitatif Kualitatif dan $R \& D$. Bandung: Alfabeta.

Sulistyo-Basuki.1993. Pengantar Ilmu Perpustakaan. Jakarta: Gramedia Pustaka Utama.

Sutarno.2006. Perpustakaan dan Masyarakat. Jakarta: Sagung Seto.

Tjiptono, Fandy. 2009. Service Marketing: esensi dan aplikasi. Yogyakarta: Marknesis. 